\title{
Impact of kidney transplantation on restless legs syndrome
}

\author{
Chrastina $\mathrm{M}^{1}$, Martinková $\mathrm{J}^{2}$, Minar $\mathrm{M}^{2}$, Zilinska $\mathrm{Z}^{1}$, Valkovic $\mathrm{P}^{2}$, Breza $\mathrm{J}^{1}$ \\ Department of Urology, Kidney transplant centre, Comenius University, School of Medicine, Slovak Medical \\ University, Bratislava, Slovakia. martin_chrastina@hotmail.com
}

\begin{abstract}
AIM: Our study was to assess the impact of kidney transplantation on restless legs syndrome (RLS) in end stage renal disease (ESRD) patients.

METHODS: A total of 75 patients after a successful kidney transplantation (39 males, 36 females) were assessed consecutively. All patients completed the self reported questionnaire focused on RLS 6 months after kidney transplantation with investigation of selected laboratory parameters. The questionnaire met the International Restless Legs Syndrome Study Group criteria for RLS diagnosis.

RESULTS: $30(40.54 \%)$ out of 75 patients met the RLS diagnostic criteria. From this RLS positive group, 8 $(26.7 \%)$ of them reported a complete regression of symptoms, $13(43.3 \%)$ reported symptoms relief, $6(20.0 \%)$ were without any change and $3(10.0 \%)$ reported worsening of symptoms after kidney transplantation. In the RLS positive group, the majority of patients (26-86.7\%) reported the occurrence of the symptoms in the evening and $21(70.0 \%)$ of RLS positive patients reported the onset of symptoms after the onset of renal disease. CONCLUSION: Although the secondary RLS in EDRS patients is very common, it is often unrecognized or misdiagnosed. We concluded that kidney transplantation, except the primary benefit to kidney replacement and to its function, has a secondary impact on other conditions such as RLS (Tab. 5, Fig. 4, Ref. 17). Text in PDF www.elis.sk.

KEY WORDS: restless legs syndrome, kidney transplantation, uremia, end-stage renal disease.
\end{abstract}

\section{Introduction}

Restless legs syndrome (RLS) is a neurological disorder first described by Karl Ekbom in 1945, characterized by irresistible urge to move legs or less likely other parts of the body. The International Restless Legs Syndrome Study Group defined criteria for the diagnosis of RLS in 1995 with their revision in 2012 (Tab. 1) (Walters, 1995, IRLSSG, 2012). RLS is categorized as either primary (idiopathic) or secondary. One of the most predominant types of secondary RLS is uremic RLS occurring in the end stage renal disease (ESRD). The prevalence of RLS in ESRD is much more higher than in idiopathic RLS and varies between 6.6 and $62 \%$ (La Manna et al, 2010) versus 7.2-9.6\% in general population (Allen et al, 2005, Hening et al, 2004). Though the aetiology of RLS is identified, patophysiology of RLS in ESRD remains still unclear. It is presumably that the low availability of iron in the central nervous system plays a key role in the patogenesis of RLS in ESRD.

Except for a higher prevalence of RLS in ESRD, the uremic RLS has some specific features such as faster deterioration, more

${ }^{1}$ Department of Urology, Kidney transplant centre, Comenius University, School of Medicine, Slovak Medical University, Bratislava, Slovakia, and ${ }^{2}$ Second Department of Neurology, Comenius University, School of Medicine, Bratislava, Slovakia

Address for correspondence: M. Chrastina, MD, Department of Urology, Kidney transplant centre, Comenius University, Slovak Medical University, Limbova 5, SK-833 05 Bratislava, Slovakia.

Phone: +421.903207227 , Fax: +421.2 .59542578$ severe symptoms, decreased response to dopaminergic agonists and higher frequency of periodic legs movement (Enamoto et al, 2008, Wetter et al, 1998).

The association of RLS among hemodialysis patients is well known, but to date only few reports or studies focusing on RLS after kidney transplantation have been reported. Therefore, the aim of our study was to assess the impact of kidney transplantation on RLS in ESRD patients and determine the risk factors.

\section{Subjects and methods}

\section{Subjects}

Seventy-five consecutive patients (39 males, 36 females), after a successful kidney transplantation were assessed. All patients were older than 18 years (median $51.14 \pm 11.12$ ). Data were collected from out-patients office of the Department of Urology, Kidney transplant centre, Comenius University, School of Medicine, Slovak Medical University, Bratislava, Slovak Republic, six months after a kidney transplantation in period from January 2013 to June 2013. At the beginning of examination all patients signed the informed consent.

\section{Data collection}

All patients underwent questionnaire-based interview focused on RLS in a period before kidney transplantation up to six month after kidney transplantation. The questionnaire met the official diagnostic criteria according to International Restless Legs Syndrome Study Group (IRLSSG 2012). The Slovak version of ques- 
Tab. 1. 2012 Revised IRLSSG diagnostic criteria for RLS (IRLSSG 2012).

An urge to move the legs usually but not always accompanied by or felt to be caused by uncomfortable and unpleasant sensations in the legs

The urge to move the legs and any accompanying unpleasant sensations begin or worsen during periods of rest or inactivity such as lying down or sitting

The urge to move the legs and any accompanying unpleasant sensations are partially or totally relieved by movement, such as walking or stretching, at least as long as the activity continues

The urge to move the legs and any accompanying unpleasant sensations during rest or inactivity only occur or are worse in the evening or night than during the day

The occurrence of the above features are not solely accounted for as symptoms primary to another medical or a behavioural condition (e.g., myalgia, venous stasis, leg edema, arthritis, leg cramps, positional discomfort, habitual foot tapping)

tionnaire had been used in previous studies on outpatients of 2 nd Department of Neurology, Comenius University, on university students and pregnant women (Valkovič et al, 2009, Martinková $\mathrm{J}$ et al, 2009, Minar et al, $2013 \mathrm{a}, \mathrm{b}$ ). The questionnaire has been slightly modified consistently with examination of patients after kidney transplantation (Tx).

The first part of questionnaire was focused on (1) demographic data (name, age, gender, the hemodialysis duration, comorbidities, regular medication, family history of RLS), (2) laboratory findings (levels of iron, phosphate, calcium, haemoglobin, albumin, glomerular filtration rate - GFR).

The second part of questionnaire was focused on (1) detection of RLS (according to IRLSSG criteria) occurring before Tx and six month after Tx retrospectively. Those, who didn't meet diagnostic criteria for RLS were assessed negative (RLS-). Responders who affirmatively met all five diagnostic criteria for RLS were considered as positive (RLS+) (2) on characteristics of RLS before Tx and 6 months after Tx (description of sensations, frequency, occurrence and time of symptoms onset, modification of RLS symptoms after kidney transplantation ).

\section{Statistical analysis}

The data were analyzed with the IBM SPSS Statistics 20 software. Descriptive statistics were used to evaluate demographic and clinical data. In order to compare the two groups (RLS+ versus RLS-), individual variables were first tested with Liliefors test (modification of the Kolmogorov-Smirnov test). If the data distribution was normal, the variables were compared between the two groups using the Student's t-test (level of significance $\alpha \leq 5 \% ; p \leq 0.05)$. For correlation statistics, Pearson's correlation coefficient was used for parametric data, $(p \leq 0.01)$, and a Spearman correlation coefficient for non-parametric variables $(\mathrm{p} \leq 0.01)$.

\section{Results}

Paients clinical characteristics and demographic data

Totally, 75 questionnaires were collected. Thirty patients (18 women, 12 men) met the clinical criteria of RLS according to
Tab. 2. The patients basic demographic and clinical characteristics (SD - standard deviation).

\begin{tabular}{lccc}
\hline & All patients & RLS+ & RLS- \\
\hline Number (\%) & $75(100)$ & $30(40.54)$ & $45(59.46)$ \\
Age (yrs \pm SD) & $51.14 \pm 11.12$ & $53.7 \pm 11.23$ & $49.39 \pm 10.67$ \\
Sex (M/F \%) & $52 \% / 48 \%$ & $40 \% / 60 \%$ & $57.78 \% / 42.22 \%$ \\
Family history of RLS (\%) & & $42.10 \%$ & \\
\hline
\end{tabular}

Tab. 3. A comparison of basic demographic data between the RLS+ and RLS- (HD-hemodialysis).

\begin{tabular}{llllc}
\hline Parameter & Group & Mean & SD & p \\
\hline \multirow{2}{*}{ Age (years) } & RLS+ & 53.70 & 11.29 & 0.05 \\
\cline { 2 - 5 } & RLS- & 49.39 & 10.67 & \\
\hline \multirow{2}{*}{ Weight (kg) } & RLS+ & 81.41 & 15.32 & 0.32 \\
\cline { 2 - 5 } & RLS- & 76.59 & 13.61 & \\
\hline Duration of HD \\
\cline { 2 - 5 } (months) & RLS+ & 38.76 & 24.95 & 0.08 \\
\hline \multirow{2}{*}{ Gender (M/F) } & RLS- & 42.23 & 33.99 & \\
\cline { 2 - 5 } & RLS+ & $40 \% / 60 \%$ & 11.29 & 0.07 \\
\hline
\end{tabular}

Tab. 4. Selected laboratory parameters of RLS+/RLS- group.

\begin{tabular}{llccc}
\hline Parameter & \multicolumn{1}{c}{ Group } & \multicolumn{1}{c}{ Mean } & SD & $\mathrm{p}$ \\
\hline Hemoglobin (g/l) & RLS+/RLS- & $128.23 / 129.86$ & $12.43 / 16.38$ & 0.32 \\
Iron (mmol/l) & RLS+/RLS- & $13.38 / 15.05$ & $3.94 / 6.15$ & 0.13 \\
Ferritin (mmol/l) & RLS+/RLS- & $551.23 / 416.52$ & $431.87 / 473.54$ & 0.16 \\
Transferrin (ng/l) & RLS+/RLS- & $1.98 / 2.06$ & $0.31 / 0.30$ & 0.18 \\
GFR(ml/min/r) & RLS+/RLS- & $59.30 / 61.30$ & $18.75 / 21.35$ & 0.34 \\
Calcium (mmol/l) & RLS+/RLS- & $2.53 / 2.51$ & $0.23 / 0.09$ & 0.36 \\
Phosphorus (mmol/l) & RLS+/RLS- & $4.45 / 1.03$ & $15.43 / 0.18$ & 0.07 \\
Parathormon (pg/ml) & RLS+/RLS- & $78.15 / 102.61$ & $37.12 / 160.80$ & 0.27 \\
Vitamin D3 (ng/l) & RLS+/RLS- & $21.60 / 24.81$ & $10.29 / 12.70$ & 0.15 \\
Creatinine (mmol/l) & RLS+/RLS- & $119.81 / 127.34$ & $44.77 / 74.44$ & 0.31 \\
\hline
\end{tabular}

definition criteria and were assessed as RLS+. The patients basic demographic and clinical characteristics are shown in Table 2. A comparison of basic demographic data (age, gender, weight, hemodialysis duration) between RLS + and RLS- group are given in Table 3.

There were significant differences in age between the RLS+ and RLS- $(p=0.05)$. Patients in RLS+ group were almost 4 years older $(53.7 \pm 11.29 \mathrm{yrs})$ than RLS- group $(49.39 \pm 10.67 \mathrm{yrs})$.

The proportion of gender between RLS + and RLS- was marginally significant $(\mathrm{p}=0.7)$. While in $\mathrm{RLS}+$ group symptoms were more prevalent in women $(\mathrm{M} / \mathrm{F}: 12 / 18=40 / 60 \% \pm 11.29)$, in RLS- group dominated men (M/F : 26/19 = 57.8/42.2\% \pm 10.50$)$.

We didn't detected any significant difference in hemodialysis duration and weight between RLS+ and RLS- .

\section{Laboratory findings}

Referring to laboratory parameters, we compared the levels of haemoglobin, iron, ferritin, trasferrin, calcium, phosphorus, parathormon, vitamin D3, creatinine and glomerular filtration rate (GFR) between RLS+ and RLS- group six months after kidney transplantation. We didn't detect any significant correlation in laboratory parameters between RLS+ versus RLS-. There were marginally significant difference in phosphorus level between these two groups $(\mathrm{p}=0.07)$ (Tab. 4). 
404-407

Tab. 5. Description of perceived dominant sensations in RLS+.

\begin{tabular}{ll}
\hline Paresthesia & Cramps \\
Tingling & Urge to move \\
Nervousness & Pressure \\
Drilling & Inching inside the legs \\
Burning & Heavy legs \\
Feet pain & Pain \\
Restlesness & Wooden legs \\
Urge to walk & Don't know \\
\hline
\end{tabular}

Characteristics and distribution of RLS symptoms

The description of perceived dominant sensations is given in Table 5.

The frequency of RLS symptoms is shown in Figure 1. It is determined as the number of days with RLS symptoms per month. Symptoms occurring 2 and more per week are considered as clinically significant and require medicament treatment (Allen, 2005). I our study, almost half of the patients $(52.18 \%$ ) suffer from RLS more than half of the month.

The majority of patients $(87 \%)$ reported the unpleasant legs sensation only in the evening hours, what is consistent with diagnostic criteria for RLS. Time of the highest occurrence of RLS symptoms during the day is shown in Figure 2.

The onset of RLS depending on kidney disease and kidney transplantation is shown in Figure $3.71 \%$ of the RLS+ group reported the onset of symptoms during kidney disease (38\% before hemodialysis and $33 \%$ during hemodialysis). $21 \%$ of patients reported the onset of symptoms before kidney disease. This may be related to primary RLS, because $42.10 \%$ of RLS + have positive family history of RLS (Tab. 1). The clinical studies revealed a positive family history in $40-90 \%$ of patients with idiopathic RLS (Minár 2013, Allen et al, 2002).

Figure 4 shows the impact of kidney transplantation (Tx) on RLS symptoms. In our study, $70 \%$ of responders reported positive effect of Tx on RLS symptoms (27\% reported complete relief and $43 \%$ amelioration of symptoms). $20 \%$ of patients reported no change and only $10 \%$ progression of symptoms. Winkelmann et al observed a complete recovery from RLS symptoms in all 11 patients after successful kidney transplantation (Winkelmann et al, 2002).

\section{Discussion}

Our study confirmed that the prevalence of RLS in patients with ESRD is significantly higher (40.54\%) than in the general population what correlates with the other studies as mentioned before.

Whereas in the RLS+ group the symptoms were more prevalent in women (60\%), men dominated in the RLS- group (almost 58 $\%$ ), what is congruent with RLS prevalence in general population with women predominance (Allen et al, 2005, Hening et al, 2004).

Patients with RLS were significantly older compared to patients without RLS. Generally, the increasing age correlates with quantity of comorbidities as well as with the risk of developing the neuropathy. However, uraemia is the main causative factor of

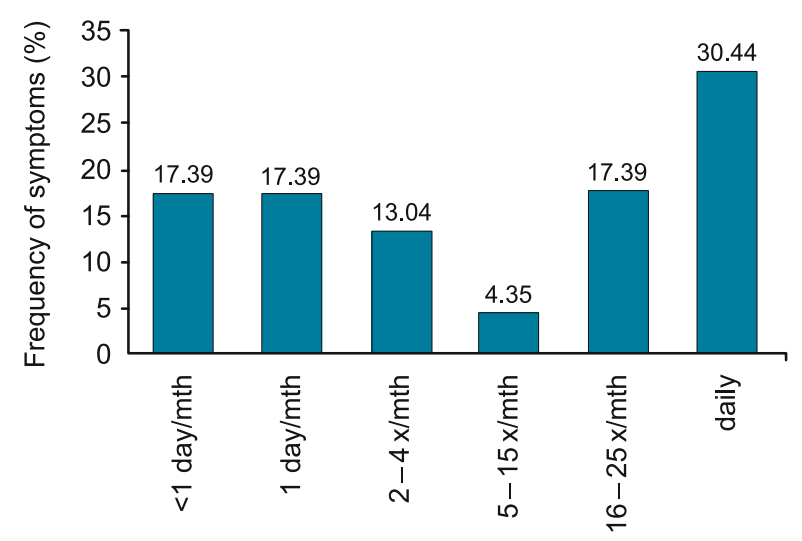

Fig. 1. The frequency of RLS symptoms given as number of days with symptoms per months in percentage (mth - month).

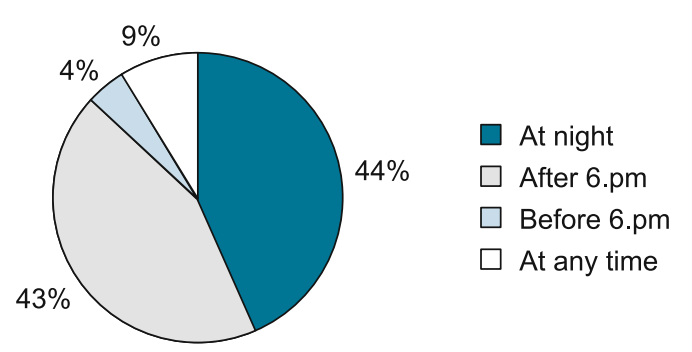

Fig. 2. Time of the highest occurrance of RLS symptoms during the day in percentage.

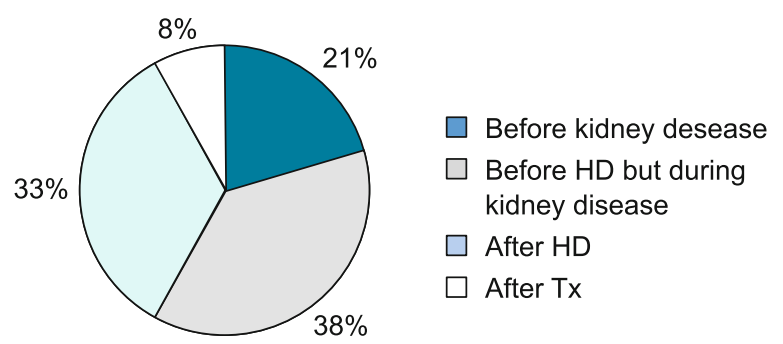

Fig. 3. The onset of RLS depending on kidney disease and kidney transplantation. (HD - hemodialysis, Tx - kidney transplantation).

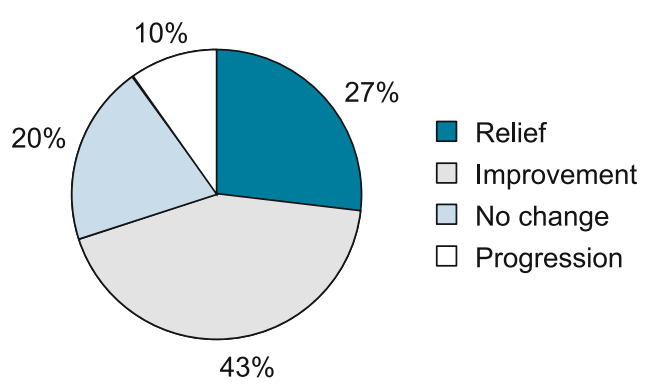

Fig. 4. Modification of RLS symptoms after kidney transplantation. 
neuropathy in ESRD patients, after kidney transplantation it used to persist or disappear very gradually contrary to RLS symptoms with fast complete recovery within 1-21 days (Winkelmann et al, 2002). Vice versa RLS symptoms reoccur within a few days after the start of hemodialysis. This underlines the fact, that the pathophysiology of RLS is still unclear, although the participation of uremic neuropathy is still relative. Marconi et al by neurophysiological investigation of group I nonreciprocal inhibition described different pathopysiological mechanism between the primary and uremic RLS. While in primary RLS spinal cord hyperexcitability was disclosed, in uremic RLS rather peripheral sensory abnormalities were detected (Marconi et al, 2012).

We didn't record any significant correlation between the laboratory parameters and the risk of RLS development in patients with kidney transplantation except of marginally significant difference in phosphorus level between RLS+ and RLS- group. In literature, the association between the biochemical parameters and the development and severity of RLS has not been yet clearly determined (Winkelmann et al, 2002). Nevertheless it is obvious, that RLS symptoms in ERDS patients are strongly associated with graft function.

\section{Treatment of RLS in ESRD}

The treatment of RLS in kidney transplant recipients is mainly based on maintaining the best possible graft function. Other therapy is similar to primary RLS including dopamine replacement therapy such as levodopa and dopamine agonists. However, uremic RLS patients seem to have a decreased response to dopaminergic agonists comparing to primary RLS patients (Enomoto et al, 2008). Gabapentin, clonazepam, benzodiazepines and opioids are further possible option for RLS treatment. Sagheb et al (2012) reported that vitamins $\mathrm{C}, \mathrm{E}$ and their combination are safe and effective treatments for reducing the severity of RLS in hemodialysis patients. From non-pharmacological treatment, aerobic exercise training may reduce RLS symptoms as well (Giannaki et al, 2013).

\section{Conclusion}

In summary, we concluded that kidney transplantation except the primary benefit by kidney replacement and its function has a secondary impact on other conditions such as RLS. Our study demonstrated that a successful kidney transplantation in end stage renal disease has a positive effect and improves the course of RLS.

\section{References}

1. Allen RP, La Buda MC, Becker P, Earley CJ. Family history study of the restless legs syndrome. Sleep Med 2002; Suppl 3: S3-7.

2. Allen RP, Walters AS, Montplaisir $\mathbf{J}$ et al. Restless legs syndrome prevalence and impact: REST genera population study. Arch Intern Med 2005; 165: 1286-1292.
3. Ekbom K. Restless legs: a clinical study. Acta Med Scand 1945; 158 : $1-123$.

4. Enomoto M, Inoue Y, Namba K, Munezawa T, Matsuura M. Clinical characteristics of restless legs syndrome in end-stage renal failure and idiopathic RLS patients. Mov Disord. 2008; 23 (6): 811-816.

5. Giannaki CD, Hadjigeorgiou GM, Karatzaferi C, Maridaki MD, Koutedakis Y, Founta P, Tsianas N, Stefanidis I, Sakkas GK. A singleblind randomized controlled trial to evaluate the effect of 6 months of progressive aerobic exercise training in patients with uraemic restless legs syndrome. Nephrol Dial Transplant 2013; 28 (11): 2834-2840.

6. Hening W, Walters AS, Allen RP, Montplaisir J, Myers A, FeriniStrambi L. Impact, diagnosis and treatment of restless legs syndrome (RLS) in a primary care population: the REST (RLS epidemiology, symptoms, and treatment) primary care study. Sleep Med 2004; 5: 237-246.

7. International Restless Legs Study Group. IRLSSG Diagnostic Criteria for RLS (2012). www.irlssg.org. Updated 2013.

8. La Manna G, Pizza F, Persici E, Baraldi O et al. Restless legs syndrome enhances cardiovascular risk and mortality in patients with end-stage kidney disease undergoing long-term haemodialysis treatment. Nephrol Dial Transplant 2011; 26 (6): 1976-1983.

9. Marconi S, Scaglione C, Pizza F, Rizzo G, Plazzi G, Vetrugno R et al. Group I nonreciprocal inhibition in restless legs syndrome secondary to chronic renal failure. Parkinsonism Relat Disord 2012; 18 (4): 362-366.

10. Martinková J, Juračičová M, Ramos Rivera GA, Valkovič P, Benetin J. Epidemiológia syndrómu nepokojných nôh v čakárni klinickej ambulancie: pilotná štúdia = Epidemiology of restless legs syndrome in a waiting-room of outpatient clinic: a pilot study. Neurológia 2009; 1: 49-51.

11. Minar M. Syndróm nepokojných nôh. Epidemiológia a klinický obraz. Dizertačná práca. Bratislava: SZU, 2013, 24 s.

12. Minar M, Valková P, Valkovič P. Prevalence and impact of restless legs syndrome in university students. Mov Disord 2013 a; 28 (8): 1157-118.

13. Minar M, Habanova H, Rusnak I, Plank K, Valkovic P. Prevalence and impact of restless legs syndrome in pregnancy. Neuro Endocrinol Lett 2013 b; 34 (5): 366-371.

14. Sagheb MM, Dormanesh B, Fallahzadeh MK, Akbari H, Sohrabi Nazari S, Heydari ST, Behzadi S. Efficacy of vitamins C, E, and their combination for treatment of restless legs syndrome in hemodialysis patients: a randomized, double-blind, placebo-controlled trial. Sleep Med 2012; 13 (5): 542-545.

15. Valkovič P, Juračičová M, Ramos Rivera GA, Martinková J, Benetin J. Vyhl'adávanie pacientov so syndrómom nepokojných nôh v čakárni klinickej ambulancie pomocou dotazníkovej metódy = Detection of patients with restless legs syndrome in a waiting-room of outpatient clinic by means of questionnaire method. Cesk Slov Neurol N 2009; 72/105 (3): $250-254$.

16. Walters A. International Restless Legs Study Group: Toward a better definition of the restless legs syndrome. Mov Disord 1995; 10: 634-642.

17. Wetter TC, Stiasny K, Kohnen R, Oertel WH, Trenkwalder C. Polysomnographic sleep measures in patients with uremic and idiopathic restless legs syndrome. Mov Disord 1998; 13 (5): 820-824.

Received May 28, 2014. Accepted January 23, 2015. 